\title{
On-farm impact analysis of resource conservation technology on wheat at Tarai-Teesta Flood plain of Eastern Indo-Gangetic Plain (IGP)
}

\author{
B. Biswas \\ Directorate of Research, Bidhan Chandra Krishi Viswavidyalaya, Kalyani, Nadia-741234 (West Bengal), INDIA \\ E-mail: kripahi@yahoo.com \\ Received: August 5, 2015; Revised received: February 25, 2016; Accepted: May 20, 2016
}

\begin{abstract}
Adoption of resource conservation technologies (RCT) may improve the productivity, reduce cost and sustainability of wheat production in the irrigated areas of eastern Indo-Gangetic plains (IGP) of South Asia. Critical on -farm study on factors favouring adoption and non-adoption is required. Findings from an on-farm trial conducted during 2005-2009 are used to evaluate the on-farm impacts of zero tillage (ZT) in wheat from three sites at Tarai-Teesta flood plain of eastern IGP. On an average, there was $11.54 \%$ increase in productivity in ZT wheat over conventional tilled (CT) wheat. Water productivity increased from $1.99 \mathrm{~kg} \mathrm{~m}-3$ in CT to $2.73 \mathrm{~kg} \mathrm{~m}-3$ in ZT due to lower estimated water use (1147 m3 ha-1 in ZT than $1435 \mathrm{~m} 3$ ha-1 in CT) and higher productivity (3.38 t ha-1 in ZT than $3.03 \mathrm{t}$ ha-1 in CT). Saving in tractor operation and diesel use in farmers' ZT wheat fields were 3.23 and 19.09 hours ha-1. Sowing can be done earlier by one week through adoption of ZT machine for better utilization of limited winter. Savings in ZT on farmers' fields were in the components of land preparation (1938 Rs ha-1), seed (462 Rs ha-1), nitrogen (269 Rs ha-1), phosphate fertilizer (104 Rs ha-1) and irrigation (380 Rs ha-1) over conventional wheat cultivation. Availability of zero-till seeder and its servicing, skilled operator and sometimes reluctance of local tiller operator for apprehension of lower earnings from single tillage pass are also revealed as the factors of non-adoption. More such in-depth studies should be conducted on site-specific basis so that it can be replicated more widely in areas for the benefit of the farming community.
\end{abstract}

Keywords: Indo Gangetic Plain, Tarai-Teesta Flood plain, Wheat, Zero tillage

\section{INTRODUCTION}

The Tarai-Teesta flood plain of the eastern part of the Indo-Gangetic Plain (IGP) is primarily a traditional rice-growing area. On medium lands, farmers used to grow pulses such as black gram, grass pea or oilseeds like toria, linseed, niger on residual moisture after harvest of long duration, photosensitive local rice. Productivity and return of those crops were low. However, due to introduction of high-yielding short duration wheat and rice in the 1970s and increasing irrigated area and improved fertilizer availability most pulses-oilseeds area have been replaced by rice and wheat ushering the green revolution (Biswas et al., 2006).

Green revolution led to production increases in all dimensions, vertical and horizontal with increase in area, productivity and intensification of cropping systems in Indian sub-continent. In Indo-Gangetic plains (IGP), farmers encouraged with higher yield of relatively short duration dwarf varieties and intensified cropping systems, improved national crop productivity especially rice and wheat to new heights. Further governments initiatives e.g. improved irrigation facilities, increased availability of fertilizers and favorable price of commodities strengthened intensive cropping and improved farm incomes (Singh et al., 2012). But recent studies indicate that this rice-wheat system is labour, water and energy intensive and it becomes less profitable as these resources become increasingly scare and the problem is aggravated with deterioration of soil health, the emergence of new weeds and challenges of climate change (Chauhan et al., 2012). Negative environmental effects related to irrigation are increasing as overexploitation of groundwater causing arsenic contamination and poor water management lead to the dropping of water tables in some areas. Agricultural technologies that can integrate environmental health, economic profitability and social equity are therefore becoming increasingly important (Brodt et al., 2011).

The rice-wheat consortium (RWC) for the IGP and later on the Cereal System Initiative for South Asia (CSISA), which is made up of international agricultural research centers, national agricultural research organizations from Bangladesh, India, Nepal and Pakistan, and advanced research institutes has developed and promoted a number of technologies that increase farm-level productivity, conserve natural resources and limit negative environmental impacts (Gupta and Sayre, 2007). These resource-conserving technologies form the basis for conservation agriculture. To date, the resource conserving technology that has been most 
Table 1. Selected wheat management indicators for $\mathrm{ZT}^{\mathrm{a}}$ and $\mathrm{CT}^{\mathrm{b}}$ plots on adopter farms in study site in West Bengal, India.

\begin{tabular}{|c|c|c|c|c|c|c|}
\hline & \multicolumn{2}{|l|}{ Jalpaiguri } & \multicolumn{2}{|l|}{ Moynaguri } & \multicolumn{2}{|l|}{ Nagrakata } \\
\hline & ZT & CT & ZT & $\mathbf{C T}$ & ZT & CT \\
\hline Total number of Tillage operations & $1.00 \mathrm{a}$ & $5.02 b$ & $1.00 \mathrm{~s}$ & $4.99 \mathrm{t}$ & $1.00 \mathrm{x}$ & $4.99 \mathrm{y}$ \\
\hline $\begin{array}{l}\text { Duration of tillageoperations (tractor } \\
\mathrm{h} \mathrm{ha}^{-1} \text { ) }\end{array}$ & $2.22 \mathrm{a}$ & $6.45 b$ & $2.39 \mathrm{a}$ & $5.12 b$ & $2.39 \mathrm{a}$ & $5.12 b$ \\
\hline Diesel consumption for tillage $\left(1 \mathrm{ha}^{-1}\right)$ & $12 \mathrm{a}$ & $32 b$ & $13 \mathrm{a}$ & $33 b$ & $13 \mathrm{a}$ & $31 b$ \\
\hline Planting duration & $25 / 11-15 / 12$ & $7 / 12-15 / 12$ & $25 / 11-15 / 12$ & $7 / 12-15 / 12$ & $2 / 12-15 / 12$ & $7 / 12-15 / 12$ \\
\hline Seed rate $\left(\mathrm{kg} \mathrm{ha}^{-1}\right)$ & 100 & 119 & 100 & 125 & 100 & 129 \\
\hline \multicolumn{7}{|l|}{ Nutrient } \\
\hline $\mathrm{N}\left(\mathrm{kg} \mathrm{ha}^{-1}\right)$ & $120 \mathrm{a}$ & $152 b$ & $120 \mathrm{~s}$ & $139 \mathrm{t}$ & $120 x$ & $170 y$ \\
\hline $\mathrm{P}\left(\mathrm{kg} \mathrm{ha}^{-1}\right)$ & 30 & 32 & 30 & 34 & 30 & 32 \\
\hline $\mathrm{K}\left(\mathrm{kg} \mathrm{ha}^{-1}\right)$ & $58 \mathrm{a}$ & $21 \mathrm{~b}$ & $58 \mathrm{~s}$ & $24 \mathrm{t}$ & $58 \mathrm{x}$ & $21 y$ \\
\hline Irrigation numbers & 3.23 & 3.27 & 3.25 & 3.33 & 3.25 & 3.33 \\
\hline Duration of irrigation $\left(\mathrm{h} \mathrm{ha}^{-1}\right)$ & $32.22 \mathrm{a}$ & $36.14 \mathrm{~b}$ & $33.13 \mathrm{~s}$ & $37.45 \mathrm{t}$ & $33.75 \mathrm{x}$ & $36.9 y$ \\
\hline $\begin{array}{l}\text { Estimated irrigation water use ( } \mathrm{m} 3 \\
\text { ha- }^{-1} \text { ) }\end{array}$ & $1162 \mathrm{a}$ & $1472 b$ & $1123 \mathrm{~s}$ & $1472 \mathrm{t}$ & $1156 x$ & $1361 \mathrm{y}$ \\
\hline
\end{tabular}

Data followed by different letters differ significantly - t-test (0.10), within row comparisons per site (n=27), ${ }^{\text {a }}$ ZT-Zero tillage;

${ }^{b} \mathrm{CT}$ - Conventional tillage

successful in the western IGP is zero tillage (ZT) planting of wheat after rice, particularly by using a tractor- drawn ZT seed drill. This specialized seeding implement allows wheat seed to be planted directly into unploughed fields with a single pass of the tractor, often with simultaneous basal fertilizer application. In contrast, conventional tillage practices for wheat in these systems involve multiple passes of the tractor to accomplish ploughing, harrowing, planking and seeding operations.

On-station and on-farm trials with ZT wheat in the rice -wheat systems of the western IGP have shown primarily positive impacts on wheat crop management, particularly through reduced input needs combined with potential yield increases. The use of ZT significantly reduces energy costs, mainly by reducing tractor costs associated with conventional methods. The use of ZT also allows the wheat crop to be planted sooner than would be possible using conventional methods, which significantly reduces turnaround time. This is an important consideration in many parts of the ricewheat belt, where late planting of wheat is a major cause of reduced yields: terminal heat implies that wheat yield potential reduces by $1-1.5 \%$ per day if planting occurs after 20 November (Hobbs and Gupta, 2003). Experimental evidence has shown that ZT reduces irrigation requirements in wheat compared to conventional at Uttar Pradesh, India (Bhushan et al., 2007). Most of the previous work has focused on northern and western IGP. Studies providing an in depth analysis on yield and cost effect analysis on onfarm ZT wheat adoptability study in the eastern IGP specially in the Terai-Teesta flood region have been initiated by the Research wing of Department of Agriculture from 2005-06 in collaboration with CSISA to understand options for adoption or non-adoption of the new technology. Here we present a quantitative evaluation of on-farm impacts of the adoption of ZT wheat of the eastern IGP in terms of variable indicators of management, productivity, economics and water use.

\section{MATERIALS AND METHODS}

Study area: The study focuses on Jalpaiguri, Nagrakata and Moynaguri the representative of Tarai-Teesta flood plain sub region $\left(12079.4 \mathrm{~km}^{2}\right)$ with average annual precipitation $3217.5 \mathrm{~mm}$. The climate is subtropical per humid with temperature index 4.0 to 8.0 , moisture index greater than 50.0 (per udic). Wheat is grown in the winter from November to March, with long term average rainfall $68.2 \mathrm{~mm}$, evaporation 389 $\mathrm{mm}$, average maximum temperature $25.9{ }^{0} \mathrm{C}$, average minimum temperature $13.1{ }^{\circ} \mathrm{C}$, average maximum relative humidity $94 \%$ and minimum relative humidity $63 \%$ during the crop season in the region. The soils in the study areas are deep, well drained, texturally coarse loamy in general and acidic in reaction. Land preparation for wheat in the study areas is mechanized using four-wheel tractors. Irrigation and chemical fertilizer use is universal. The delay in planting the wheat crop is mainly due to the late harvest of the previous crop and/or a long turnaround time. The late harvest of the previous rice crop can be linked to both the late rice establishment and the duration of the rice crop. The long turnaround time often reflects intensive tillage operations, soil-moisture problems (too wet or too dry), and non-availability of traction power for ploughing.

Data sources: This study interprets ZT as the planting of wheat with a tractor-drawn ZT seed drill directly into unploughed fields with a single pass of the tractor. The main primary data source for this study was a formal survey of rice-wheat growers from Tarai-Teesta flood zone. The adoption survey used a stratified sampling frame. Altogether three villages per location were randomly chosen from Jalpaiguri, Moynaguri and Nagrakata Block. Within each selected village, nine farm households were chosen randomly. This gave a total of 27 farm households in each location for ZT and CT each. Each selected household was visited twice during 2005-2009 to collect detailed information using 
Table 2. Selected wheat productivity indicators management indicators for ZT and CT plots on adopter farms in study site in West Bengal, India.

\begin{tabular}{|c|c|c|c|c|c|c|}
\hline & \multicolumn{2}{|c|}{ Jalpaiguri } & \multicolumn{2}{|c|}{ Moynaguri } & \multicolumn{2}{|c|}{ Nagrakata } \\
\hline & $\overline{Z T}$ & $\mathbf{C T}$ & $\overline{Z T}$ & $\mathbf{C T}$ & $\overline{Z T}$ & CT \\
\hline Grain yield (t ha- $\left.{ }^{1}\right)$ & $3.56 \mathrm{a}$ & $3.22 b$ & $3.3 \mathrm{~s}$ & $2.99 \mathrm{t}$ & $3.29 \mathrm{x}$ & $2.89 \mathrm{y}$ \\
\hline Irrigation water productivity & & & & & & \\
\hline t irrigation ${ }^{-1}$ & 1.10 & 0.98 & 1.02 & 0.90 & 1.01 & 0.87 \\
\hline $\mathrm{kg}$ irrigation $\mathrm{m}^{-3}$ & $3.06 \mathrm{a}$ & $2.19 \mathrm{a}$ & $2.94 \mathrm{~s}$ & $2.03 \mathrm{t}$ & $2.85 \mathrm{x}$ & $2.12 \mathrm{y}$ \\
\hline Gross water productivity (rain + irrigation $)\left(\mathrm{kg}\right.$ irrigation $\left.\mathrm{m}^{-3}\right)$ & $2.84 \mathrm{a}$ & $2.06 \mathrm{a}$ & $2.72 \mathrm{~s}$ & $1.91 \mathrm{t}$ & $2.64 \mathrm{x}$ & $1.99 \mathrm{y}$ \\
\hline
\end{tabular}

Data followed by different letters differ significantly - t-test $(0.10)$, within row comparisons per site $(\mathrm{n}=27)$.

Table 3. Crop budget for ZT and CT plots on adopter farms in study site in West Bengal, India.

\begin{tabular}{|c|c|c|c|c|c|c|}
\hline & \multicolumn{2}{|c|}{ Jalpaiguri } & \multicolumn{2}{|c|}{ Moynaguri } & \multicolumn{2}{|c|}{ Nagrakata } \\
\hline & ZT & CT & ZT & CT & ZT & CT \\
\hline A. Gross revenue (grain and straw, $\mathrm{Rs} \mathrm{ha}^{-1}$ ) & $29477 \mathrm{a}$ & $26662 b$ & $27324 s$ & $24757 \mathrm{t}$ & $27241 x$ & $23929 y$ \\
\hline B. Total cost $\left(\mathrm{Rs} \mathrm{ha}^{-1}\right)^{\mathrm{a}}$ & $17825 \mathrm{a}$ & $20554 b$ & $17814 \mathrm{~s}$ & $19845 \mathrm{t}$ & $17868 \mathrm{x}$ & $19907 y$ \\
\hline Cost of land preparation & $1332 \mathrm{a}$ & $3870 \mathrm{~b}$ & $1434 \mathrm{~s}$ & $3072 \mathrm{t}$ & $1434 x$ & $3072 y$ \\
\hline C. Net revenue (A-B, Rsha ${ }^{-1}$ ) & $11652 \mathrm{a}$ & $6108 b$ & $9510 \mathrm{~s}$ & $4912 t$ & $9373 x$ & $4022 y$ \\
\hline Benefit :cost ratio $(\mathrm{A} / \mathrm{B})$ & $1.65 \mathrm{a}$ & $1.30 \mathrm{~b}$ & $1.53 \mathrm{~s}$ & $1.25 \mathrm{t}$ & $1.52 \mathrm{x}$ & $1.20 \mathrm{y}$ \\
\hline Production cost $\left(\mathrm{Rs} \mathrm{kg}^{-1}\right)$ & $5.01 \mathrm{a}$ & $6.38 \mathrm{~b}$ & $5.40 \mathrm{~s}$ & $6.64 \mathrm{t}$ & $5.43 \mathrm{x}$ & $6.89 y$ \\
\hline Financial water productivity (Rs gross revenue) ${ }^{\mathrm{b}}$ & $23.55 \mathrm{a}$ & $17.07 \mathrm{~b}$ & $22.54 \mathrm{~s}$ & $15.85 \mathrm{t}$ & $21.87 \mathrm{x}$ & $16.50 \mathrm{y}$ \\
\hline
\end{tabular}

Data followed by different letters differ significantly - $\mathrm{t}$-test $(0.10)$, within row comparisons per site ( $\mathrm{n}=27)$; ${ }^{\mathrm{a}}$ Total cost includes land preparation and crop establishment; fertilizer; plant protection; irrigation; harvesting; land rent and interest ${ }^{\mathrm{b}} \mathrm{Net}$ revenue/ (rain+irrigation water).

a structured questionnaire covering various indicators at the farm and plot levels as indicated by Keil et al. (2015) \& Erenstein (2009). On adopters' farms where farmers had used both ZT and conventional tillage for their wheat crop, both plots were surveyed.

Analytical methods: Surveyed farm households were classified based on their use of ZT in wheat. The farmers who were following ZT wheat since 2005-06 and used ZT for wheat during rabi 2008-2009 also were classified as adopters. Those who never used ZT for wheat on their farm were classified as non-adopters. Finally, those farmers who had used ZT in the past, but not in rabi 2008-2009, were classified as disadopters. ZT wheat has been primarily adopted by the larger and more productive farmers in the all study areas. The structural differences between the adopters and nonadopters/disadopters in terms of resource base, crop management and performance thereby easily confound the assessment of ZT impact across adoption categories. Indeed, there are significant differences between the surveyed wheat plots of adopters (irrespective of whether ZT or conventional wheat) and non-adopters and disadopters (data not sown), but these can therefore not be attributed to ZT. Partial ZT adoption prevails and thereby enables us to limit ourselves to adopter farms. The plot-level comparisons reported here will therefore focus on the comparison of the ZT and conventional plots of adopters only. This comparison is more objective in view of the underlying resource base and management differentials with two caveats. The water productivity analysis follows the water productivity framework developed by (Molden et al., 1998). The main inflow components of the study area and considered in this study are irrigation from the canal and tube-well sources and rainfall. The water inflow indicators draw from farmer recall plot-level data for number and duration of irrigations by source (canal and tube well). These were converted into water volumes using average irrigation volumetric rates and seasonal rainfall in the study area. Water productivity was estimated on the basis of the yield and monetary value per unit of the estimated irrigation inflow and gross inflow (irrigation + rain).

The financial analysis was done per individual surveyed household using the reported physical input/ output levels and local farm prices that prevailed at the time of the survey (Jat et al., 2014). Prices are reported financial market prices, including eventual taxes and subsidies. These market rates are assumed to be a reliable reflection of opportunity costs, irrespective of ownership (e.g., in case of land and tractors) and facilitate comparison.

\section{RESULTS AND DISCUSSION}

The conventional wheat establishment practice involves an average of five tractor tillage passes and broadcasting of wheat. The survey results show that ZT reduces tractor operations in farmers' ZT wheat fields to a single pass, implying a per ha saving of 4.23, 2.73 and 2.73tractor hours and 20.04, 19.68 and 17.561 of diesel in Jalpaiguri, Moynaguri and Nagrakata, respectively (Table 1). Sowing can be done earlier by one week through adoption of ZT machine. Yield increased around $10 \%$ in ZT over CT $(10.56 \%$ at Jalpaiguri, $10.37 \%$ at Moynaguri and $13.84 \%$ at $\mathrm{Na}-$ grakata) (Table 2). To put the survey year in perspective, wheat yields under ZT and conventional tillage on all surveyed farms were also compiled for last four 
seasons. The data for the four years show the same trend. (Fig. 1). The water use indicators from the adoption survey for ZT and conventional wheat were significantly different in all sites (Table 1 ). ZT reduced the duration of the first tube-well irrigation in the study site. The higher yield in combination with the nonsignificant irrigation numbers still result in significantly higher physical water productivity indicators for ZT wheat compared to conventional wheat in all the locations (Table 3). This survey highlighted that ZT for wheat saves first irrigation time on compact soil, saves irrigation water and enhances wheat yield but ZT again did not significantly reduce the number of irrigations. Our findings confirm the drastic reduction in tillage intensity in farmer fields when shifting from conventional to ZT. Earlier diagnostic studies reported (Sharma et al., 2012) an average of six tillage operations in Punjab and eight tillage operations in Haryana, followed by another tractor cultivation after broadcasting. Our study highlights that the current conventional practices four times tillage operations on an average and final plunking to cover the broadcasted seeds. In spite of advantage of tillage intensity, broadcasting still the major practice in the surveyed study area. Mechanized ZT area has increased to some extent in proximity to the study sites where the facilities have been provided to the farmers. Therefore, contrary to expectations, the diffusion of ZT has, so far, not resulted in reduction in "conventional" tillage intensity intensively. The drastic reduction in tillage operations does translate into equally pronounced differences in number of tractor hours and diesel use. The corresponding costs savings in land preparation and establishment are the main contributor to the significant "cost-saving effect' of ZT in all the sites. The ZT-induced diesel savings are also particularly attractive to farmers in view of high oil prices. The diesel savings also imply a significant positive environmental externality by reducing $\mathrm{CO}_{2}$ emissions, a significant contributor to global warming. The use of the ZT drill is potentially seed saving compared to broadcasting, without any yield loss. Fertilizer use efficiency in ZT is also higher than CT for point placement near crop root zone resulting minimum sharing of nutrients to undisturbed weed seed bank as well as minimizing fertilizer loss through volatilization. ZT wheat adaptor farms followed the recommended balanced fertilizers using mostly the mixture of complex fertilizer (N:P: K ::10:26:26@ kg $\mathrm{ha}^{-1}$ ) and urea but conventional wheat receives imbalanced nutrients with higher nitrogen and phosphorus but lower potassium in the region surveyed. The ZTinduced time savings in land preparation resulted one week early crop establishment, with significant differences in planting dates between ZT and conventional wheat in the limited cold span region of Eastern IGP. Delayed sowing of wheat is common in this area for late plating of preceding wet season rice resulting delayed harvesting, excess soil moisture in low and medium land and even excess dry soil in the upland situation, sometimes delayed reseeding of rain or even early onset of winter increasing turnaround time for wheat sowing under conventional system.

Yield effects: A positive yield effect of ZT is often associated with more timely wheat establishment (Saharawat et al., 2010). In South Asia late planted wheat is subject to terminal heat stress whereas timely planted wheat has a correspondingly longer growing period. Both sites indeed highlight a significant and similar negative correlation between wheat yield and sowing date in surveyed plots (Julian day number, correlation coefficient: $0.15, \mathrm{p}=0.00)$. Wheat plots established before 16 November yielded significantly more (200 kg ha ${ }^{-1}$ ) compared to plots established thereafter in both sites. However, as mentioned above, although ZT reduces turnaround time, there was no significant difference in terms of time of wheat establishment between ZT and conventional plots in the survey year. This suggests that farmers have generally been reluctant to significantly advance their wheat planting date despite apparently increased opportunities to do so with ZT. Earlier on-farm experiments in Pakistan showed that compared to conventional, ZT wheat improved the crop stand and yielded 10-40\% higher under different soil types and wheat-sowing regimes (Ahmad et al., 2014).Late establishment still is a major contributor to low wheat productivity in study areas. The potential of ZT to significantly alleviate untimeliness only partially materialized and can be better utilized both in terms of early establishment. More emphasis should be placed by development
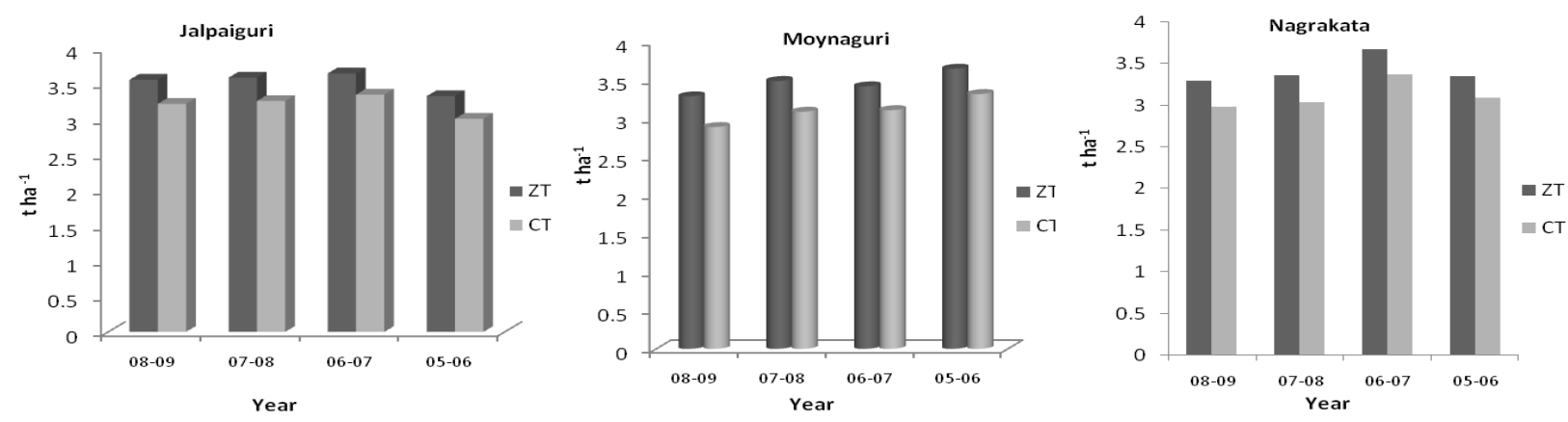

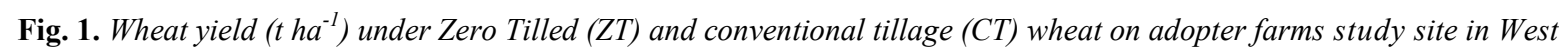
Bengal, India ( $n=27$ in each location). 


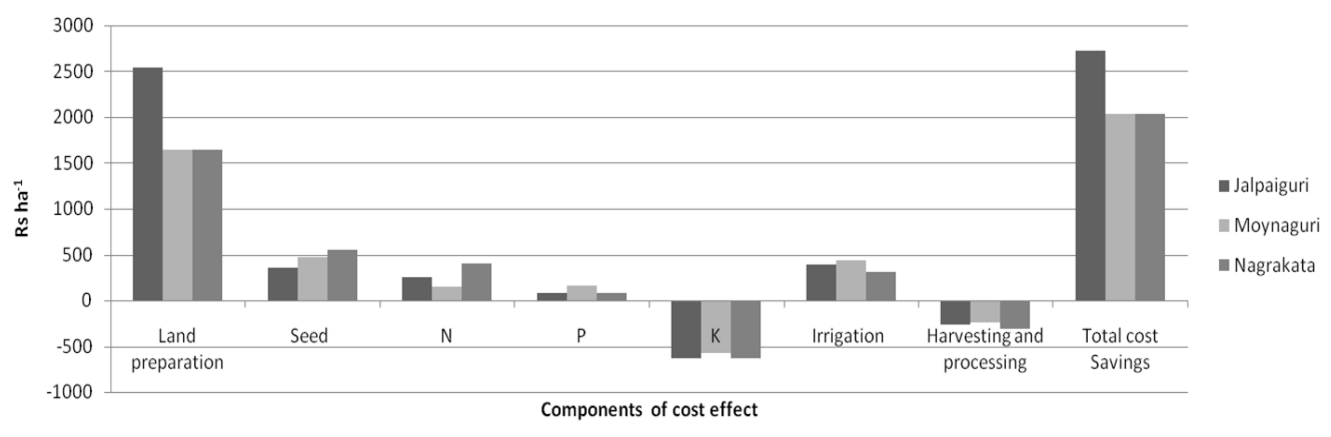

Fig. 2. Component cost effect (Rs. ha $\left.{ }^{-1}\right)$ in Zero Tilled (ZT) over conventional tillage (CT) wheat on adopter farms study site in West Bengal, India ( $n=27$ in each location).

agents on highlighting the enhanced timeliness aspect of ZT, which would further boost the returns to adopting ZT and alleviate yield concerns apart from improved soil health (Mandal et al., 2015).

Water effects: Water is a major concern for the sustainability of intensive wheat cultivation in the IGP. Experimental evidence has shown that ZT reduces irrigation requirements in wheat compared to conventional (Chauhan et al., 2012). ZT uses residual soil water more effectively. With ZT irrigation, water spreads faster across the surface, whereby irrigation can be stopped once the field is covered. ZT potentially improves the soil structure and facilitates the build-up of surface soil organic matter, which has been linked to increased water retention, better infiltration and reduced overall water use. In addition, the faster turnaround time made possible by ZT allows the wheat crop to be planted and harvested earlier, potentially reducing the need for one or more late-season irrigations in some areas.

Particularly the water use survey supports the postulated water saving nature of ZT wheat at the field scale. Perhaps somewhat disappointingly, the adoption surveys could not unambiguously verify that ZT generated significant water savings. In part, this is likely due to measurement errors in view of our survey estimates, which are subject to farmer recall and where we cannot control for all underlying sources of variation. These confounding effects may mask some of the ZT effects, if any. Nonetheless, the farmer responses imply there is some water saving, but maybe less significant than often alluded. The adoption survey did confirm that ZT reduces the duration of the first tube-well irrigation in both sites, which is associated with irrigation water flow in faster over untilled fields. Consequently, generally less irrigation water is applied to ZT during the first irrigation. This is generally beneficial as, in tilled fields, often too much water is applied to parts of the field resulting in waterlogging and yellowing of wheat plants.

The present study concurs with other studies that resource conservation technologies like ZT can be successful in improving field-scale irrigation efficiency through irrigation savings. However, as highlighted by Ahmad et al. (2007), whether or not improved irrigation efficiency translates to 'real' water savings depends on the hydrologic interactions between the field and farm, the irrigation system and the entire river basin. In fact, the water saving impacts of resource conservation technologies beyond the field level are not well understood and documented." For instance, some of the irrigation water "saved" would be simply recycled, percolating into the groundwater table from where it would later be reused by farmers through pumping. These calls for more systematic assessments of water balance components at farm to system scales. In any event, the irrigation water savings with $\mathrm{ZT}$ in wheat are still modest, and are insufficient to address the impending water crisis. To put the water savings for ZT wheat further in perspective it is useful to recall that irrigation expenses for summer rice is a multiple of that of wheat of 17.7 times in a field experiment at Eastern IGP (Biswas et al., 2006). The current attraction of ZT in wheat indeed primarily relates to the cost savings and not the water savings as such. This is likely to remain as long as farmers are not charged according to their actual water use and do not pay the real (economic) cost of water. But this implies making politically unpopular adjustments to (ground) water rights and the subsidy and taxation schemes (e.g., flat water charges, underpriced/free irrigation water, incentive structure geared towards rice and wheat) that currently undermine the sustainability of rice-wheat systems. Technological intervention thus needs to be complemented with policy reform to create an enabling environment for sustainable agriculture that includes crop rotation and promotes economic resource use. This could easily prove more significant, particularly for water savings.

Financial impact of ZT: ZT wheat plots in all three locations show significantly lower total costs and significantly higher gross and net revenues than conventional. Compared to the conventional plots of adopters, ZT shows a net advantage of Rs. $5544 \mathrm{ha}^{-1}$, Rs. 4598 $\mathrm{ha}^{-1}$ and Rs. $5351 \mathrm{ha}^{-1}$ at Jalpaiguri, Moynaguri and Nagrakata, respectively, composed of a yield effect of 
Rs. $2815 \mathrm{ha}^{-1}$, Rs $2567 \mathrm{ha}^{-1}$ and Rs $3312 \mathrm{ha}^{-1}$ and a cost-saving effect of Rs. 2729 ha $^{-1}$, Rs. $2031 \mathrm{ha}^{-1}$ and Rs $2039 \mathrm{ha}^{-1}$ (Table 2). Among the components of cost effects (pooled over the locations), saving on land preparation was the highest $(86 \%)$ followed by seed (20\%) and irrigation (17\%) (Fig. 2). Farmers of the survey site have general tendency of using more nitrogen and phosphorus and less potash. Balanced nutrient application in ZT farms resulted cost saving of $12 \%$ in nitrogen, $5 \%$ in potassium but $27 \%$ higher in potassium application. Harvesting and processing cost also in ZT farms was $12 \%$ higher over the CT to handle the higher yield. Compared to conventional plots of adopters, ZT wheat plots also achieved a higher return on production costs, lower production cost per $\mathrm{kg}$ grain and higher financial water productivity (Table 3 ). The financial implications of a new technology are a major determinant of technological change. The combination of a significant "yield effect" and "cost-saving effect" makes ZT adoption for wheat worthwhile and is the main driver behind the rapid spread and widespread acceptance of Z. The ZT "cost-saving effect" seems robust enough to make adoption worthwhile and is the driver behind the prior spread of ZT amongst adopters in Punjab (Farooq et al., 2007) and Bihar (Keil et al., 2015). However, learning costs eat into the cost-saving effect and may undermine the apparent returns to adoption for prospective adopters, particularly in view of the lack of a positive yield effect. Timely availability of trained operator, ZT machines, is also a problem in the study area. The relatively minor net revenues derived from wheat cultivation in some plots underscore the need for continued yield enhancement and cost savings to maintain wheat competitiveness in rice-wheat systems. It also highlights the relative significance of the ZT-induced income enhancement, which boosts returns well above breakeven and it is an environment-benign technology (Bhan and Behera, 2014).

\section{Conclusion}

The combination of a significant "yield effect" with average $11.54 \%$ higher productivity and "cost- saving effect" in terms of land preparation (1938 Rs ha $\left.{ }^{-1}\right)$, seed (462 Rs ha ${ }^{-1}$ ), nitrogen (269 Rs ha $\left.{ }^{-1}\right)$, phosphate fertilizer (104 Rs ha ${ }^{-1}$ ) and irrigation (380 Rs ha ${ }^{-1}$ ) over conventional makes ZT adoption worthwhile and provide a much needed boost to the returns to wheat cultivation in Eastern IGP replacing summer rice which requires higher ground water along with additional problem of arsenic contamination. The prime driver for ZT adoption is monetary gain in both sites with added advantages of higher water productivity and lower carbon footprint. However, some technical problems with large-scale adoption of no-till system are associated crop establishment besides availability of zero-till seeder, availability of compatible high power tractor. Sometimes lack of knowledge in machinery operation leads to poor seed distribution and improper stand establishment. Hired tractor driver are sometimes reluctant for their lower earning for decreasing number of tillage operations. However, with awareness and knowledge of package of practices, these issues can be tackled for widespread adoption of this cost saving technology.

\section{ACKNOWLEDGEMENTS}

The authors wish to acknowledge the active cooperation of on-site West Bengal Government Agricultural Extension Officials Mr. S. Sil, Mr. G. Berma and Dr S. Mitra Majumder for their support in the survey works. The original studies were funded by the Rice Wheat Consortium, CYMMIT and Cereal Systems Initiative for South Asia, CGIAR through Department of Agriculture, Government of West Bengal.

\section{REFERENCES}

Ahmad, M.D., Turral, H., Masih, I., Giordano, M. and Masood, Z. (2007). Water saving technologies: myths and realities revealed in Pakistan's rice-wheat systems. IWMI Research Report 108. International Water Management Institute, Colombo, SriLanka.

Ahmad, M., Masih, L and Giordano. (2014). Constraints and opportinies for water savings and increasing productivity through Resource Conservation Technologies in Pakistan. Agriculture, Ecosystem \& Environment. 187: 106-132.

Biswas, B., Ghosh, D.C., Dasgupta, M.K., Trivedi, N., Timsina, J. and Dobermann, A. (2006). Integrated assessment of cropping systems in the Eastern Indo-Gangetic plain. Field Crops Research. 99: 35-47.

Bhan, S. and Behera. (2014). Conservation agriculture in India Problems, prospects and policy issues. International Soil and Water Conservation Research. 2(4): 1-12.

Bhushan, L., Ladha, J.K., Gupta, R.K., Singh, S, Tirol-Padre, A., Saharawat, Y.S., Gathala, M. and Pathak, H. (2007). Saving of water and Labour in a Rice-Wheat System with No-Tillage and Direct Seeding Technologies. Agronomy Journal. 99:1288-1296.

Brodt, S., Six, J., Feenstra, G., Ingels, C. and Campbell, D. (2011). Sustainable Agriculture. Nature Education Knowledge. 3(10):1-8.

Chauhan, B.S., Mahajan, G., Sardana, V, Timsina, J. and Jat, M.L. (2012). Productivity and sustainability of the Rice-Wheat Cropping System in the Indo-Gangetic Plains of the Indian subcontinent: Problems, Opportunities, and Strategies. Advances in Agronomy. 117:315-369.

Erenstein, O. (2009). Specification effects in zero tillage survey data in South Asia's rice - wheat system. Field Crops Research. 111: 166-172.

Farooq, U., Sharif, M. and Erenstein, O. (2007). Adoption and impacts of zero tillage in the rice-wheat zone of irrigated Punjab, Pakistan. Research Report. CIMMYT India \&RWC, NewDelhi, India.

Gupta, R. and Sayre, K. (2007). Conservation agriculture in South Asia. J. Agric. Sci. 145: 207-214.

Hobbs, P.R., Gupta and R.K. (2003). Rice-wheat cropping systems in the Indo- Gangetic Plains: issues of water productivity in relation to new resource- conserving 
technologies. In: Kijne, J.W., Barker, R. and Molden, D. (Eds.), Water Productivity in Agriculture: Limits and Opportunities for Improvement. CABI Publication, Wallingford, UK, pp.239-253.

Jat, R.K., Sapkota, T.B., Singh, R.G., Jat, M.L., Kumar. M.and Gupta, R.K. (2014). Seven years of conservation agriculture in a rice-wheat rotation of Eastern Gangetic Plains of south Asia: Yield trends and economic profitability. Field Crop Research. 164:199-210

Keil, A.K., D'souza, A. and McDonald, A. (2015). Zerotillage as a pathway for sustainable wheat intensification in the Eastern Indo-Gangetic Plains: does it work in farmers' fields? Food Security. 7(5): 983-1001.

Mandal, S.K., Kumar, R., Kumar, S., Singh, Y.K. and Kumar, R. (2015). Impact of resource conservation technologies on soil health and productivity of wheat in rice-wheat cropping system. Journal of Applied and Natural Sciences. 7(1): 58-66.

Molden, D.J., Sakthivadivel, R.,Perry, C.J.,de Fracture, C. and Kloezen, W.H. (1998). Indicators for comparing performance of irrigated agricultural systems. Research Report 20. International Water Management Institute (IMWI), Colombo, Sri Lanka.

Saharawat, Y.S., Singh, B., Malik, R.K., Ladha, J.K., Gathala, M., Jat, M.L., Kumar, V. (2010). Evaluation of alternative tillage and crop establishment methods in a rice-wheat rotation in North Western IGP. Field Crops Research. 116: 260-267.

Sharma, A.R., Jat, M.L., Saharawat, Y.S., Singh, V.P., \& Singh, R. (2012). Conservation agriculture for improving productivity and resource-use efficiency: prospects and research needs in Indian context. Indian Journal of Agronomy, 57 (IAC Special Issue): 131-140.

Singh, R.G., Mishra, S.K., Singh, P.K., Jat, R.K., Dey, S., Shahi, V.B., Lahiri, A., Biswas, B., Sarkar, S., Bhattacharya, P., Kumar, S. and Gupta, R.K. (2012). Opportunities for managing rice-fallow systems with conservation agricultural technologies. Indian Farming 62(6): 31 -34, 40 September, 2012. 